\title{
Dental caries experience and its impact on quality of life in Latin American and Caribbean countries
}

Saul Martins PAIVA ${ }^{(a)}$

Ninoska ABREU-PLACERES(b)

María Esther Irigoyen

CAMACHO(c) (D)

Antonio Carlos FRIAS(d) iD

Gustavo TELLO(e) (iD

Matheus França PERAZZO(a) (iD

Gilberto Alfredo

PUCCA-JÚNIOR ${ }^{(\text {f) }}$ iD

(a) Universidade Federal de Minas Gerais UFMG, School of Dentistry, Department of Pediatric Dentistry, Belo Horizonte, MG, Brazil.

(b) Universidad Iberoamericana, Biomaterials and Dentistry Research Center (CIBO-UNIBE), Academic Research Department, Santo Domingo, Dominican Republic.

(c) Universidad Autónoma Metropolitana, Health Care Department, Xochimilco, México.

(d) Universidade de São Paulo - USP, School of Dentistry, Department of Community Dentistry, São Paulo, SP, Brazil.

(e) Norbert Wiener University, Department of Pediatric Dentistry, Lima, Peru.

(f) Universidade de Brasília - UnB, Faculdade de Ciências da Saúde, Department of Dentistry, Brasília, Brazil.

Declaration of Interests: The authors certify that they have no commercial or associative interest that represents a conflict of interest in connection with the manuscript.

Corresponding Author:

Saul Martins Paiva

E-mail:smpaiva@uol.com.br

ht1ps://doi.org/10.1590/1807-3107bor-2021.vol35.0052

Submitted: March 3, 2021

Accepted for publication: March 9, 2021

Last revision: March 10, 2021

\begin{abstract}
Robust epidemiological data allow for logical interventions taken in the interest of public health. Dental caries is a major public health problem driven by increased sugar consumption and various biological, behavioral, and psychosocial factors, and is known to strongly affect an individual's quality of life. This study aims to critically review epidemiological data on the prevalence of dental caries in Latin American and Caribbean countries (LACC) and its impact on the oral health-related quality of life (OHRQoL) of the population. Although the majority of national surveys did not include all age groups and several countries reported a reduction in the prevalence of cavitated carious lesions, most nations still exhibited a high burden of decayed teeth. OHRQoL evaluation was limited to children and older adults only, and was not included in any national survey. Study heterogeneity and methodological issues hindered comparison of evidence between studies and over time, and updating national level data on caries prevalence and its impact on OHRQoL should be prioritized in LACCs.
\end{abstract}

Keywords: Dental Caries; Epidemiology; Quality of Life; Latin America; Caribbean Region.

\section{Introduction}

Epidemiological survey data is useful for the prevention, control, and eradication of various health problems, serving as an essential tool for development of public policy and planning of interventions aimed at promotion of health. ${ }^{1}$ Oral health plays a crucial role in the well-being of a population and, when compromised, can affect an individual's quality of life by causing pain and loss of esthetics/function leading to absenteeism from work/schools and low self-esteem. ${ }^{2}$ The dental caries pandemic is driven by an increase in the consumption of refined sugars and changes in eating patterns and social behaviors. ${ }^{3}$

Untreated carious lesions are one of the most frequently observed oral health problems globally, with prevalence rates being $100 \%$ and $80 \%$ among 12 year old adolescents in low-income and lower-middle-income countries, respectively. ${ }^{4}$ Moreover, such lesions often persist into adulthood, with disease burden increasing with the number of teeth in the oral cavity. The global burden of untreated caries lesions in permanent teeth 
was 2.3 billion people, and regarding untreated caries in primary teeth, 532 million children were affected worldwide. ${ }^{5}$

However, the prevalence of dental caries has decreased in several countries, resulting in polarization of the disease and higher rates being observed among deprived populations. ${ }^{6,7}$ The last two decades of the 20th century and the first two decades of the 21st century were characterized by massive structural, demographic, and social changes in developing countries [particularly Latin American and Caribbean countries (LACC)], with intense urbanization, progression of the population demographic to increased life expectancy and higher proportions of elderly individuals, and changes in nutritional patterns to include increased intake of calorific, industrialized, and ultra-processed foods resulting in higher prevalence of obesity, compromised quality of life, and variations in the way diseases affected populations. ${ }^{8}$

Dental caries management can prove to be challenging, particularly in developing countries that exhibit higher disease prevalence. ${ }^{5,9}$ A systematic review and meta-analysis of studies examining children aged 5-6 years and adolescents aged 11-13 years in LACCs concluded that more than $50 \%$ of the study population exhibited dental caries. ${ }^{10}$ In fact, the tropical Latin American region was shown to exhibit the highest prevalence of untreated dental caries in the world. ${ }^{11}$

However, there is limited data available on the older populations in this region, and this information is particularly important when considering the demographic transition occurring in Latin America. The Survey of Health and Well-Being of Elders carried out among adults aged 60 years and above from seven cities in LACCs showed that approximately $97.5 \%$ of the participants had lost their teeth (although these rates were lower among those with higher educational attainment) and exhibited greater need for dental treatment. ${ }^{12}$

Dental caries is a socially determined disease and is directly affected by various behavioral, social, and demographic factors, ${ }^{7,13}$ and the management of this disease by individuals, health professionals, and public managers can substantially affect the patient's quality of life. ${ }^{14}$ The Oral Health-Related Quality of Life (OHRQoL) is a multidimensional, complex, and dynamic construct formed by a subjective evaluation of how oral health can impact an individual's functional and emotional well-being and their expectations of and satisfaction with care and the sense of care. ${ }^{15}$ Therefore, OHRQoL is subject to changes over time and is also sensitive to the social, cultural, and political context. ${ }^{16}$

Dental caries can negatively affect OHRQoL in different age groups, with developing countries and underprivileged populations being the worst affected. Poor oral health can negatively affect an individual's ability to perform essential activities, such as chewing, speaking, smiling, limit their ability to attend work/school and compromise their psychological well-being. ${ }^{17}$ The oral health of an individual plays a crucial role in their overall general well-being and is considered to be an important determinant of their quality of life. ${ }^{18}$

Evaluation of the prevalence of dental caries in LACCs and its impact on OHRQoL is essential as it can provide an evidence base for policymakers, dental professionals, and individuals committed to the improvement of oral public health in these countries through the implementation of effective prevention and health promotion measures. ${ }^{19}$ Therefore, this study aims to critically review epidemiological evidence on the prevalence of dental caries in LACCs and its impact on the population's OHRQoL.

\section{Methodology}

\section{Search strategy}

Studies on the prevalence of dental caries in LACCs were identified through systematic searches conducted on the following databases: MEDLINE, EMBASE, LILACS, and Google Academic. Additionally, the World Health Organization Dental Databank and the official LACC Ministry of Health websites were also searched. Manual searches were carried out using the Medical Subject Heading descriptor "Dental Caries", the qualifier "Epidemiology", and the key words "dental treatment needs" and "oral health surveys" combined with the terms "Latin America and the Caribbean" and "Central America and South America". Additionally, individual 
country names, including Mexico in North America; Belize, Costa Rica, El Salvador, Guatemala, Honduras, Nicaragua, and Panama in Central America; Antigua and Barbuda, Aruba, Bahamas, Barbados, Bonaire, Cayman, Dominica, Dominican Republic, Guadalupe, Haiti, Jamaica, Saint Lucia, Saint Kitts and Nevis, Saint Martin, Saint Vincent and Grenadines, Island Grenada, Navassa Island, Saba, Nueva Esparta, Puerto Rico, Trinidad and Tobago, and Turks and Caicos in the Caribbean; and Argentina, Brazil, Bolivia, Chile, Colombia, Ecuador, French Guiana, Guiana, Paraguay, Peru, Suriname, Venezuela, and Uruguay in South America, were also combined with the keywords to identify relevant studies. A systematic literature search using the keywords "oral health-related quality of life" and "dental caries" combined with the names of the different regions and countries listed above was also carried out using the databases mentioned previously. The literature search was completed in August 2020, and the titles, authors, and dates of publication were reviewed to eliminate duplicates.

\section{Eligibility criteria}

The eligibility criteria used for the identification of relevant studies have been listed below:

a. National level surveys were prioritized and, when unavailable, the largest and most recent studies were selected;

b. All age groups were included;

c. Studies evaluating dental caries using the World Health Organization (WHO) Criteria were selected;

d. Manuscripts published in Spanish, English, or Portuguese were included.

Publications that met the above criteria were selected for further abstract review, and studies focusing on caries prevalence and DMFT/dmft (Decayed, Missing and Filled Teeth) scores were included. Therefore, the current review excluded studies that did not use the WHO caries criteria. ${ }^{20}$ For this method, the stages of caries that precede cavitation as well as other conditions similar to the early stages of caries were not used in these epidemiological surveys. Studies examining special needs or institutionalized participants were not included in this review. ${ }^{21}$
Literature searches were carried out by five researchers focusing on the Central American, Caribbean, and South American regions. Any differences in opinions and doubts with regard to the literature search and study selection process were clarified through discussion between four authors (SP, NA, EI, GT). Although national surveys were prioritized, such evidence was unavailable in some countries and smaller studies examining dental caries was selected in these situations (Figure 1). Table shows the results of dental caries surveys in LACCs, while Figure 2 provides further information on DMFT levels (as per the WHO criteria) among 12 year old population. ${ }^{21}$

\section{Results}

\section{Data for Latin American countries}

The average DMFT score for 12 year old adolescents in Brazil was 2.1 in 2010, ${ }^{22}$ and this was $25 \%$ lower than the DMFT score (2.8) observed in 2003. ${ }^{23}$ There was a $29 \%$ reduction (1.7-1.2) in the untreated (decayed) teeth component, and the proportion of caries-free children (DMFT $=0$ ) increased from 31\% in 2003 to $44 \%$ in 2010, indicating a significant reduction in the prevalence and severity of caries caused by widespread implementation of preventive measures and improved access to dental restorative services during this period. Additionally, decreasing prevalence of caries and increased access to services was also observed among adolescents (15-19 years old) and adults (35-44 years old), with the average DMFT scores decreasing by 19\% from 20.1 in 2003 to 16.8 in $2010 .{ }^{23}$ A significant increase of $69 \%$ (from 4.2 to 7.3 ) in the filled teeth component of the DMFT index was also observed, and this was associated with a $50 \%$ decrease in the missing teeth component. ${ }^{22,23}$

In Ecuador, national surveys focusing on children and adolescents aged 6, 12, and 15 years were conducted in $1996^{24}$ and $2010,{ }^{25}$ and a reduction in the prevalence of dental caries (from $88.2 \%$ to $75.6 \%$ of the total sample) was observed in all age groups. ${ }^{24,25}$ The Peruvian National Survey of children and adolescents conducted in $2002^{26}$ reported caries prevalence and $\mathrm{dmft}$ scores of $87.3 \%$ and 6.7 , respectively, among 6 year old children. The corresponding scores among 12 year old adolescents were $86.6 \%$ and 3.67 , respectively. 


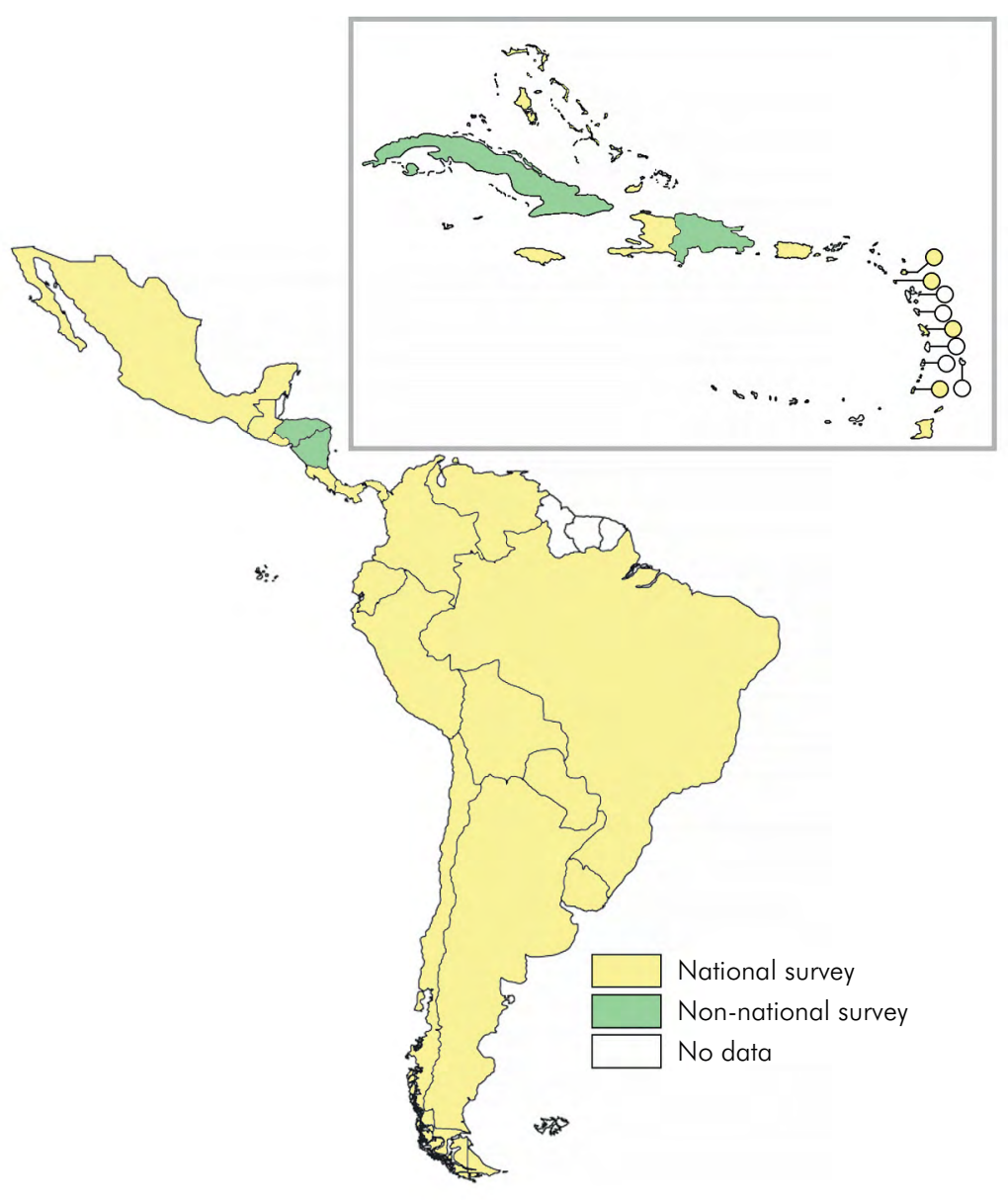

Figure 1. Representativeness of epidemiological studies in Latin American and Caribbean countries.

The national surveys of children and adolescents in Colombia were performed in 1998 and 2014, and a reduction in the prevalence of caries (from 2.30 to 1.51) was observed among 12 year old adolescents over this time period. ${ }^{27,28} \mathrm{~A}$ similar reduction in caries prevalence was also observed in the same age groups in Chile in 1992 and 2007,, ${ }^{29}$ and in Paraguay in 1999 and $2008{ }^{30}$ The 1997 National Survey in Bolivia reported a dmft score of 7.9 among 6 year old children and a DMFT score of 4.7 among 12 year old adolescents, while the most recent national survey conducted in 2015 reported a slight decrease in these scores ( $\mathrm{dmft}$ : 7.2, DMFT: 4.6). ${ }^{31}$ Similarly, Guatemala ${ }^{32}$ reported a DMFT score of 4.51 and 6.88 in the 12 and 15 year age groups, respectively.

Although differences in data and study periods were observed between national oral health studies conducted in Argentina (2014), ${ }^{33}$ Venezuela (2008) ${ }^{34}$ and
Uruguay $(1992,2011), 35,36$ a comparison of the DMFT scores showed a worrying outcome for Argentina where the DMFT score (3.0) of children aged 12 years in 2014 was similar to that of Uruguay (4.1) in 1992 and higher than that of Venezuela (1.23) in 2008. This highlights the need for prioritizing improvement of oral health conditions in public health policies, particularly in countries with high DMFT/dmft scores.

The first national survey of children and adolescents in Mexico was conducted in $2001^{37}$ and the caries prevalence and $\mathrm{dmft}$ scores at the age of 6 were found to be $64.5 \%$ and 3.06 , respectively. Heterogeneous results were observed in the various states of the country, with the highest scores being observed in the central area of Mexico. The majority of 12 and 15 year old adolescents exhibited dental caries, with prevalence rates being $58 \%$ and $68 \%$, respectively. Moreover, approximately two teeth were affected 
Table. Descriptive analysis of dental caries in LACC.

\begin{tabular}{|c|c|c|c|c|c|c|c|c|c|c|}
\hline Country & Year & $\begin{array}{l}\text { Representativeness } \\
\text { (type of sample) }\end{array}$ & Calibration & Index & Sample & $\mathrm{D}(\mathrm{d})$ & $M(m)$ & $F(f)$ & $\begin{array}{l}\text { DMFT [SD] } \\
\text { (dmft) }\end{array}$ & Prevalence (\%) \\
\hline \multirow{3}{*}{ 1.Argentina } & \multirow{3}{*}{2014} & \multirow{3}{*}{ National survey } & \multirow{3}{*}{ Yes } & \multirow{3}{*}{ DMFT } & 6 & \multirow{3}{*}{-} & \multirow{3}{*}{ - } & \multirow{3}{*}{ - } & - & $6(74,4)$ \\
\hline & & & & & 12 & & & & 3.0 & $12(70.0)$ \\
\hline & & & & & Total (7785) & & & & & \\
\hline \multirow{2}{*}{ 2. Bolivia } & \multirow{2}{*}{2015} & \multirow{2}{*}{ National survey } & \multirow{2}{*}{ Yes } & \multirow{2}{*}{$\begin{array}{l}\text { DMFT } \\
(\mathrm{dmft})\end{array}$} & 6 & \multirow{2}{*}{ - } & \multirow{2}{*}{-} & \multirow{2}{*}{-} & (7.2) & \multirow{2}{*}{ - } \\
\hline & & & & & 12 & & & & 4.6 & \\
\hline \multirow{6}{*}{ 3. Brazil } & \multirow{6}{*}{2010} & \multirow{6}{*}{ National survey } & \multirow{6}{*}{ Yes } & & $5(7217)$ & (2.03) & $(0.06)$ & $(0.33)$ & (2.43) & $5(53.4)$ \\
\hline & & & & & 12 (7247) & 1.21 & 0.12 & 0.73 & 2.07 & $12(56.5)$ \\
\hline & & & & DMFT & 15-19 (5367) & 1.7 & 0.38 & 2.16 & 4.25 & 15-19 (76.1) \\
\hline & & & & (dmfft) & $35-44$ (9564) & 1.94 & 7.48 & 7.33 & 16.75 & $35-44$ (99.1) \\
\hline & & & & & 65-74 (7509) & 0.62 & 25.29 & 1.62 & 27.53 & 65-74 (99.8) \\
\hline & & & & & Total (36904) & & & & & \\
\hline & & & & & 6 & 1.95 & 1.52 & 0.24 & (3.71) & $6(70.4)$ \\
\hline & & & & & 12 & 0.75 & 1.04 & 0.11 & 1.9 & $12(62.5)$ \\
\hline 4. Chile & 2007 & National survey & Yes & $\begin{array}{l}\text { DMFT } \\
\text { (dmff) }\end{array}$ & 15 & & & & 3.0 & 15 (73.9) \\
\hline & & & & & $35-44$ & - & - & - & 15.1 & $35-44(99.2)$ \\
\hline & & & & & $65-74$ & & & & 21.6 & 65-74 (99.4) \\
\hline & & & & & 5 & & & & $(2.82)$ & $5(52.2)$ \\
\hline & & & & & 12 & & & & 1.51 & $12(37.45)$ \\
\hline & & & & & 15 & & & & 2.35 & 15 (44.49) \\
\hline 5 Colombia & 2014 & Nationgl survey & Yes & DMFT & $20-34$ & - & - & - & 5.98 & $20-34(52.81)$ \\
\hline 5. Colomida & 2014 & INamonal survey & Tes & (dmfft) & $35-44$ & - & - & - & 11.05 & $35-44(64.73)$ \\
\hline & & & & & $45-64$ & & & & 15.25 & $45-64(61.11)$ \\
\hline & & & & & 65-79 & & & & 20.55 & 65-79 (43.47) \\
\hline & & & & & Total (34843) & & & & & \\
\hline & & & & & $6-8(1260)$ & - & - & - & - & $6-8(75.2)$ \\
\hline & & & & & 6 & (2.15) & $(0.46)$ & $(0.77)$ & (3.38) & $6(70.6)$ \\
\hline & & & & & 7 & $(1.87)$ & $(0.55)$ & $(1.12)$ & (3.54) & 7 (78.9) \\
\hline 6. Costa Rica & 1999 & National survey & Yes & $\begin{array}{l}\text { DMFT } \\
\text { (dmft) }\end{array}$ & 8 & (1.61) & $(0.49)$ & $(0.95)$ & (3.05) & $8(74.1)$ \\
\hline & & & & & $12(1260)$ & 0.72 & 0.09 & 1.65 & 2.46 & $12(71.9)$ \\
\hline & & & & & 15 (1260) & 0.96 & 0.18 & 3.23 & 4.37 & $15(82.6)$ \\
\hline & & & & & Total (3780) & & & & & \\
\hline & & & & & $6(700)$ & (3.62) & $(0.08)$ & $(0.92)$ & $(4.62)$ & 6 (79.9) \\
\hline 7. Ecuador & 2010 & National survey & Yes & DMFT & 12 (822) & 0.94 & 0.11 & 0.56 & 1.61 & $12(60.8)$ \\
\hline & & trandinal survey & & (dmft) & $15(826)$ & 1.57 & 0.33 & 1.09 & 2.99 & $15(71.5)$ \\
\hline & & & & & Total (4358) & & & & & \\
\hline & & & & & 12 (2863) & & & & 4.51 & - \\
\hline 8. Guatemala & 2002 & National survey & Yes & DMFT & 15 (1 138) & - & - & - & 6.88 & - \\
\hline & & & & & Total (4001) & & & & & \\
\hline & 2014 & National Survey* & & & $6(18262)$ & $(2.25)$ & $(0.08)$ & $(0.34)$ & $(2.67)$ & $6(61.29)$ \\
\hline & & & & & $12(21740)$ & 0.86 & 0.01 & 0.24 & 1.11 & $12(46.73)$ \\
\hline & & & & & 15 (15469) & 1.28 & 0.03 & 0.37 & 1.68 & 15 (52.31) \\
\hline 9. Mexico & & & Yes & (dmft) & & & & & & \\
\hline & 2019 & $\begin{array}{l}\text { National Survilance } \\
\text { system (SIVEPAB)** }\end{array}$ & & & $35-44$ (45818) & 7.05 & 2.18 & 3.04 & 12.27 & $35-44(94.26)$ \\
\hline & & & & & 65-74 (15409) & 5.78 & 9.53 & 2.78 & 18.04 & 65-74 (97.94) \\
\hline
\end{tabular}


- Dental caries experience and its impact on quality of life in Latin American and Caribbean countries

\begin{tabular}{|c|c|c|c|c|c|c|c|c|c|c|}
\hline Country & Year & $\begin{array}{l}\text { Representativeness } \\
\text { (type of sample) }\end{array}$ & Calibration & Index & Sample & $D(d)$ & $M(m)$ & $F(f)$ & $\begin{array}{l}\text { DMFT [SD] } \\
\text { (dmft) }\end{array}$ & Prevalence (\%) \\
\hline \multirow{8}{*}{ 10. Nicaragua } & \multirow{8}{*}{2002} & \multirow{8}{*}{ Leon city survey } & \multirow{8}{*}{ Yes } & \multirow{8}{*}{$\begin{array}{l}\text { DMFT } \\
\text { (dmft) }\end{array}$} & 6 & \multirow{8}{*}{ - } & \multirow{8}{*}{-} & \multirow{8}{*}{ - } & 0.11 (3.59) & $6(72.6)$ \\
\hline & & & & & 7 & & & & $0.13(3.97)$ & - \\
\hline & & & & & 8 & & & & $0.36(3.66)$ & - \\
\hline & & & & & 9 & & & & $0.60(2.90)$ & - \\
\hline & & & & & 10 & & & & $0.82(0.82)$ & - \\
\hline & & & & & 11 & & & & $1.00(1.61)$ & - \\
\hline & & & & & 12 & & & & 1.51 & $12(45.5)$ \\
\hline & & & & & Total (1400) & & & & & \\
\hline \multirow{2}{*}{ 11. Panama } & \multirow{2}{*}{2008} & \multirow{2}{*}{ National survey } & \multirow{2}{*}{ Yes } & \multirow{2}{*}{$\begin{array}{l}\text { DMFT } \\
\text { (dmft) }\end{array}$} & $6-12$ & 2.64 & 0.61 & 0.16 & 3.1 & $6-12(62.3)$ \\
\hline & & & & & 6-75 (12061) & 2.79 & 5.23 & 2.16 & 10.18 & 6-75 (86.9) \\
\hline \multirow{3}{*}{ 12. Paraguay } & \multirow{3}{*}{2008} & \multirow{3}{*}{ National survey } & \multirow{3}{*}{ Yes } & \multirow{3}{*}{$\begin{array}{l}\text { DMFT } \\
(\text { dmft })\end{array}$} & 6 & $(5.34)$ & $(0.18)$ & (0.39) & $(5.57)$ & $6(90.0)$ \\
\hline & & & & & 12 & 2.24 & 0.26 & 0.29 & 2.79 & 12 (75.6) \\
\hline & & & & & 15 & 3.29 & 0.53 & 0.50 & 4.34 & 15 (81.5) \\
\hline \multirow{4}{*}{ 13. Peru } & \multirow{4}{*}{2002} & \multirow{4}{*}{ National survey } & \multirow{4}{*}{ Yes } & & $6(1280)$ & $(6.0)$ & $(0.4)$ & $(0.3)$ & $(6.66)$ & $6(87.27)$ \\
\hline & & & & DMFT & 12 (1291) & 3.3 & 0.2 & 0.2 & 3.67 & $12(86.64)$ \\
\hline & & & & (dmft) & 15 (1297) & 4.7 & 0.5 & 0.7 & 5.90 & $15(91.40)$ \\
\hline & & & & & Total (7730) & 5.10 & 0.37 & 0.37 & 5.84 & Total (90.43) \\
\hline & 1992 & National survey & & & $6(1164)$ & & & & (3.9) & \\
\hline & & & & & $12(573)$ & & & & 4.1 & \\
\hline 14. Uruguay & 2011 & National survey & Yes & $\begin{array}{l}\text { DMFT } \\
\text { (dmft) }\end{array}$ & 15-24 (418) & - & - & - & 4.1 & - \\
\hline & & & & & $35-44(229)$ & & & & 15.2 & \\
\hline & & & & & 65-74 (275) & & & & 24.1 & \\
\hline & & & & & 6 & & & & $(2.27)$ & \\
\hline 15 Venezuela & 2008 & National survey & Yes & DMFT & 12 & - & - & - & 1.23 & - \\
\hline 10. veriezueta & 2000 & 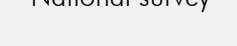 & Tes & (dmft) & $35-44$ & - & - & - & 9.47 & - \\
\hline & & & & & $65-74$ & & & & 21.40 & \\
\hline & & & & $\mathrm{SiC}$ & $6(485)$ & $(2.31)$ & $(0.10)$ & $(0.04)$ & $(2.45)$ & $253(52.2)$ \\
\hline 16. Antigua \& & 2006 & National survey & Yes & $\begin{array}{l}\text { DMFT } \\
(\text { dmft })\end{array}$ & 12 (699) & 0.76 & 0.10 & 0.04 & 0.90 & 251 (35.9) \\
\hline & & & & & $15(351)$ & 1.62 & 0.25 & 0.05 & 1.92 & $126(53.0)$ \\
\hline & & & & & Total (1535) & & & & & \\
\hline & & & & & $5(1060)$ & $(2.22)$ & & $(0.20)$ & $(2.42)$ & $5(58.0)$ \\
\hline 17 Dobamo & ק & Nationd a & & DMFT & $12(865)$ & 1.30 & - & 0.26 & 1.56 & $12(54.5)$ \\
\hline . & 2000 & 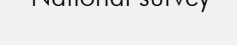 & Tes & (dmft) & 15 (759) & 1.62 & & 0.36 & 1.98 & 15 (61.0) \\
\hline & & & & & Total (2684) & & & & & \\
\hline & & & & & 6-7 (82) & & & & 0.07 & $6-7(6.1)$ \\
\hline & & & & & 8-9 (123) & & & & 0.6 & 8-9 (35.0) \\
\hline 18. Cuba & 2000 & Havana survey & No & $\begin{array}{l}\text { DMFT } \\
\text { (dmft) }\end{array}$ & 10-104) 11 (104) & - & - & - & 0.8 & 10-11(40.4) \\
\hline & & & & & 12-13 (105) & & & & 1.1 & $12-13$ (44.8) \\
\hline & & & & & Total (414) & & & & & \\
\hline & & & & & 12-14 (227) & 6.0 & 0.09 & 1.40 & 7.49 & - \\
\hline 19. Dominican & 2008 & Santo Domingo & $Y_{0 s}$ & $\mathrm{n}_{2}$ & 15-17 (572) & 6.78 & 0.16 & 1.72 & 8.66 & - \\
\hline Republic & 2000 & survey & res & DIVII I & 18-21 (133) & 8.38 & 0.53 & 1.03 & 9.94 & - \\
\hline & & & & & Total (932) & & & & & Total (90.02) \\
\hline
\end{tabular}




\begin{tabular}{|c|c|c|c|c|c|c|c|c|c|c|}
\hline Country & Year & $\begin{array}{l}\text { Representativeness } \\
\text { (type of sample) }\end{array}$ & Calibration & Index & Sample & $D(d)$ & $M(m)$ & $F(f)$ & $\begin{array}{c}\text { DMFT [SD] } \\
\text { (dmft) }\end{array}$ & Prevalence (\%) \\
\hline \multirow{3}{*}{ 20. Grenada } & \multirow{3}{*}{2010} & \multirow{3}{*}{ National survey } & \multirow{3}{*}{ Yes } & \multirow{3}{*}{$\begin{array}{l}\text { DMFT } \\
\text { (dmft) }\end{array}$} & $6-8(652)$ & $1(9.69)$ & $0(1.94)$ & $0.03(0.09)$ & 1.03 (1 1.72) & - \\
\hline & & & & & 14-15 (439) & $6.55(0.05)$ & $1.44(0)$ & $0.41(0)$ & $8.4(0.05)$ & - \\
\hline & & & & & Total (1091) & & & & & \\
\hline \multirow{3}{*}{ 21. Haiti } & \multirow{3}{*}{2005} & \multirow{3}{*}{ National survey } & \multirow{3}{*}{ Yes } & \multirow{3}{*}{$\begin{array}{l}\text { DMFS } \\
\text { (dmfs) }\end{array}$} & $12(1260)$ & 0.72 & 0.09 & 1.65 & 2.46 & 12 (71.9) \\
\hline & & & & & 15 (1260) & 0.96 & 0.18 & 3.23 & 4.37 & 15 (82.6) \\
\hline & & & & & Total (2520) & & & & & \\
\hline \multirow{7}{*}{ 22. Jamaica } & \multirow{7}{*}{1995} & \multirow{7}{*}{ National survey } & \multirow{7}{*}{ Yes } & \multirow{7}{*}{ DMFT } & 6 & \multirow{7}{*}{-} & \multirow{7}{*}{ - } & \multirow{7}{*}{ - } & 0.22 & - \\
\hline & & & & & 7 & & & & 0.47 & - \\
\hline & & & & & 8 & & & & 0.41 & - \\
\hline & & & & & 6-8 (377) & & & & - & $6-8$ (18.3) \\
\hline & & & & & 12 (359) & & & & 1.08 & $12(41.0)$ \\
\hline & & & & & 15 (377) & & & & 3.02 & 15 (74.53) \\
\hline & & & & & Total (1 1113$)$ & & & & & \\
\hline 23. Martinique & 1991 & National survey & Yes & DMFT & $12(301)$ & - & - & - & 6.3 & 12 (75.0) \\
\hline 24. Montserrat & 2007 & National survey & Yes & DMFT & $12(32)$ & 1.53 & 0.06 & 0.31 & 1.91 & $12(59.0)$ \\
\hline $\begin{array}{l}\text { 25. Puerto } \\
\text { Rico }\end{array}$ & 2011 & National survey & Yes & DMFT & 12 (1587) & 0.75 & 0.075 & 1.675 & 2.5 & $12(69.0)$ \\
\hline \multirow{4}{*}{$\begin{array}{l}\text { 26. Trinidad \& } \\
\text { Tobago }\end{array}$} & \multirow{4}{*}{2006} & \multirow{4}{*}{ National survey } & \multirow{4}{*}{ Yes } & \multirow{4}{*}{ DMFT } & 6-8 (788) & 2.19 & 0.28 & 0.007 & 2.54 & $6-8(72.0)$ \\
\hline & & & & & $12(488)$ & 0.43 & 0.07 & 0.11 & 0.61 & $12(59.0)$ \\
\hline & & & & & 15 (328) & 0.67 & 0.10 & 0.29 & 1.06 & $15(65.0)$ \\
\hline & & & & & Total (1604) & & & & & \\
\hline
\end{tabular}

*1 1 out of 32 states in Mexico included non-cavitated caries lesions. ${ }^{* *}$ Ministry of Health, Specific Action Program for the Prevention, Detection and Control of Oral Disease 2019-2024. Preliminary document, August 2020.

by caries $(\mathrm{DMFT}=1.91)$ by the age of 12 , and $17.8 \%$ of the index score could be attributed to filled teeth. The distribution of DMFT components was similar in the 15 year age group. The second National Mexican Survey was conducted between 2011 and $2014^{38}$ and the results have been presented in Table 1. A decrease in the $\mathrm{dmft}$ index (3.06 to 2.67) of primary dentition in children aged 6 years old was observed and, interestingly, the distribution of the components was seen to change. A slight increase in the proportion of filled teeth (from $9.2 \%$ to $14.1 \%$ ) and a noticeable decreased in missing primary teeth (from $25.8 \%$ to $2.6 \%$ ) was seen to occur between 2001 and 2014. In this second survey, 11 out of 32 Mexican states included cavitated and non-cavitated carious lesions in the decayed component of the caries index when examining permanent dentition. ${ }^{38}$ Despite this, the caries index scores were found to be lower in the 2014 survey compared to the 2001 survey (1.91 vs 1.11) among children aged 12 years old. This was accompanied by a change in the distribution of the components, with the proportion attributed to the filled component increasing from $17.8 \%$ to $28.3 \%$. However, treatment needs remained high, with the largest component of the index formed by untreated carious lesions. Dental caries data for the adult population in Mexico is available from the National Surveillance System, ${ }^{39}$ which collects its information from dental surveillance services around the country. In 2019, caries prevalence was higher than $90 \%$ among individuals aged 35 years and above, while more than half of the DMFT index score was derived from decayed teeth (57.5\%) in the 35-44 years age group. Among patients aged 65-74 years and older, missing teeth formed approximately $52.8 \%$ of the DMFT index. Fac-to-face interviews collecting information on edentulism at the national levels found that $25.5 \%$ of the $65-74$ year age group did not have any natural teeth. ${ }^{40}$

The 2008 National Survey in Panama reported a $\mathrm{dmft}$ score of 5.05 among children aged 6 years old, and 


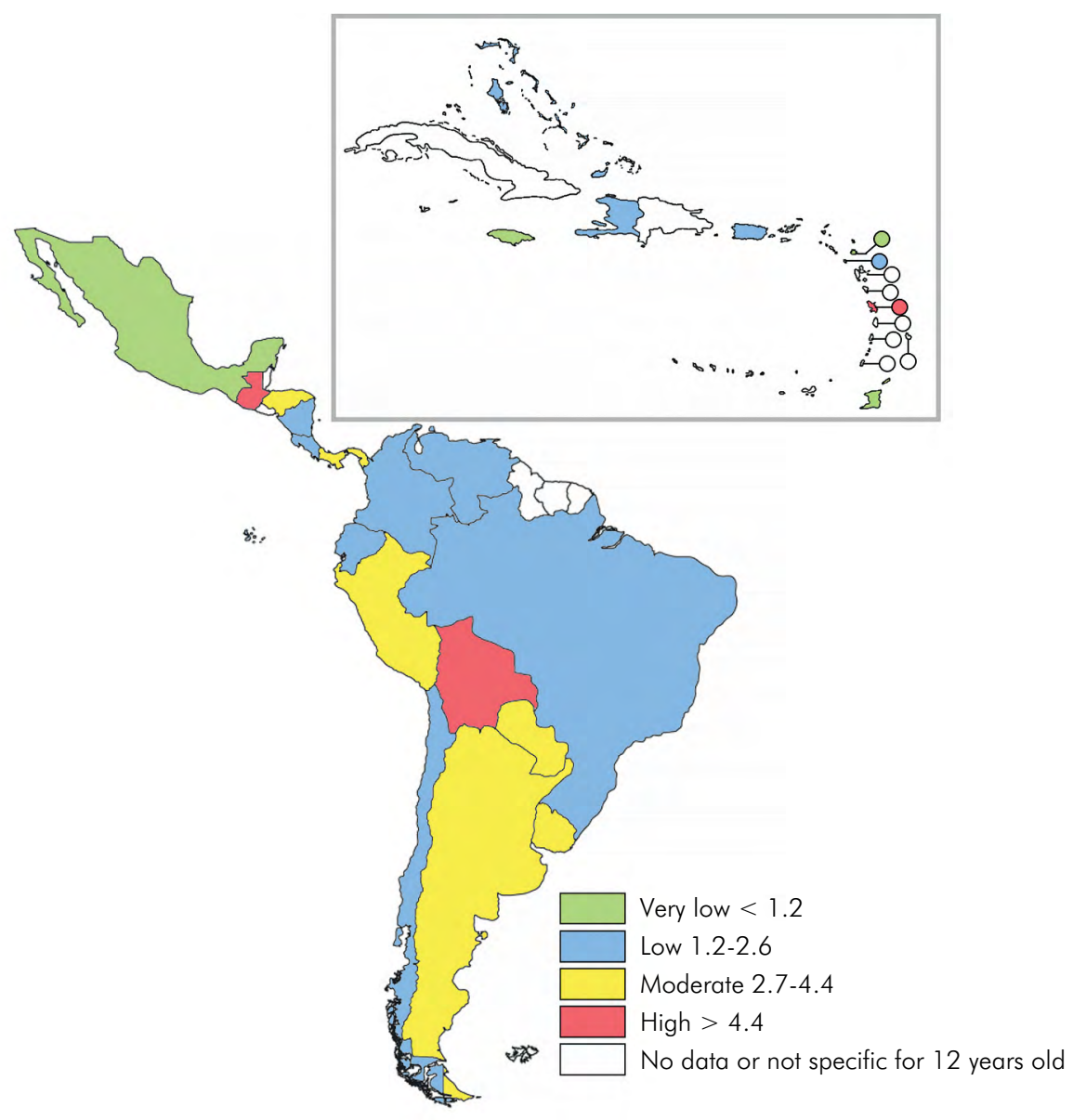

Figure 2. Prevalence of dental caries [DMFT: Decayed, Missing and Filled Teeth index] among children aged 12 years in Latin American and Caribbean countries.

higher values were observed in rural and indigenous communities. The corresponding DMFT scores were 3.97 among children aged 12 years and 10.18 in the whole population (6 to 75 years old). Of this, $27.4 \%$ were attributed to decayed teeth and approximately one fifth $(21.2 \%)$ to filled teeth. The need for prosthetic rehabilitation was high among the adult population. ${ }^{41}$ The national survey conducted in El Salvador in 2000 reported dmft scores of 4.0 among children aged 6 years old, and more than $90 \%$ of the index could be attributed to the decayed component. This was also true for 12 and 15 year old adolescents, with more than half of the index score being attributed to decayed teeth (Table 1). Data from a dental program conducted in a rural community in 2006 indicated that all children aged 6 years old exhibited dental caries, while a more recent study reported high rates of dental caries among primary teeth and very low prevalence of restored teeth among children in rural communities. ${ }^{42}$

Data on dental caries prevalence in Honduras, is scarce, with a mission dentistry community program conducted in 2017 reporting very high caries index scores in primary teeth (8.7 and 3.7 in children aged 5-6 years and 12 years, respectively) ${ }^{43}$ In comparison, a previous study conducted in 1997 reported DMFT scores of 4.51 among children aged 12 years old, suggesting a decrease in caries prevalence over time. ${ }^{44}$ A 1999 national survey in Costa Rica reported data for the populations of 6-8, 12, and 15-year-olds. Results indicated a mean $\mathrm{dmft}$ of 3.32 for $6-8$ year-olds with a dental caries prevalence of $75.2 \%$ on the primary dentition. Additionally, the mean DMFT scores of the three age groups were $0.49,2.46$, and 4.37 , respectively, while the dental caries prevalence among the 12 and 
15 year age groups were 71.9 and $82.6 \%$, respectively. ${ }^{45}$ Another national study conducted in 2006 reported a mean DMFT score of 2.57 and caries prevalence of $84.4 \%$ among adolescents aged 12 years old. ${ }^{46} \mathrm{~A}$ Nicaraguan study conducted in schools located in the City of Leon followed the methodology proposed by the WHO and reported a mean $\mathrm{dmft}$ score of 3.54 and a dental caries prevalence of $77.6 \%$ among children aged 6-9 years. ${ }^{47}$ Using the same criteria, another study examining children aged 9-12 years reported a mean DMFT score of 0.98 and prevalence rate of $37.9 \%{ }^{48}$

\section{Data for Caribbean countries}

The Caribbean region in America is also known as the West Indies and comprises of territories around the Caribbean Sea. Cuba has the largest population and the most extensive territorial dimension in the Caribbean region. In a rural community in the province of La Havana, the DMFT scores of children aged 6-7 years and 12-13 years were 0.07 and 1.1, respectively, in 1997. The prevalence rates for dental caries in the same were $6.1 \%$ and $44.8 \%$, respectively. ${ }^{49}$ A national study performed in 2005 in Haiti, which has the second largest population in the region, reported a mean DMFT score of 2.46 in the 12 year age group and 4.37 in the 15 year age group. The prevalence of dental caries in these groups were $71.9 \%$ and $82.6 \%$, respectively. ${ }^{50}$ A previous study reported a DMFT score of 4.4 among children aged 12 years in the Dominican Republic in $1997,{ }^{51}$ while another study conducted in the capital of Santo Domingo reported a mean DMFT score of 7.4 and dental caries prevalence of $90 \%$ among $12-14$ year old adolescents in 2008. ${ }^{52} \mathrm{~A}$ multi-stage national study conducted in 2011 in Puerto Rico, a territory of the USA, reported a mean DMFT score of 2.5 and dental caries prevalence of $69 \%$ among 12 year old adolescents ${ }^{53}$ indicating a reduction in disease prevalence upon comparison to data from another national study conducted in $1997 . .^{54}$ The 2011 study showed a reduction in the values of the $D$ and $M$ components, and an increase in the values of the $\mathrm{F}$ component. A Jamaican national study conducted in 1995 reported mean DMFT scores of 0.22, 1.08, and 3.02 among children aged 6,12 , and 15 years, respectively. The dental caries prevalence in these groups were $18.3 \%, 41 \%$, and $74.5 \%$, respectively. ${ }^{55}$ In Antigua and Barbuda, ${ }^{56}$ the dmft score among 6 year old children was 2.45 , while the mean $\mathrm{dmft}$ scores in the Republic of Trinidad and Tobago were 2.83 among children aged 3-5 years in 2014 and 2.54, 0.61 and 1.06 among the $6-8,12$, and 15 years age groups in 2004, respectively. In 2014, the dental caries prevalence in Trinidad and Tobago was 50.3\% in the primary dentition of children aged 3-5 years old, while the corresponding numbers in the 6-8, 12 , and 15 year age groups were $72 \%, 59 \%$, and $65 \%$, respectively. ${ }^{57,58}$

There is very limited epidemiological data on dental caries prevalence in the less populated countries of the Caribbean region. A national study in Martinique reported a mean DMFT score of 6.3 and dental caries prevalence of $75 \%$ among 12 year old adolescents in $1991,{ }^{59}$ while another national study conducted in the Bahamas in 2000 reported mean dmft scores of 2.42, 1.56 and 1.98 and dental caries prevalence rates of $58 \%$, $54.5 \%$, and $61 \%$ among 5 year old children and 12 and 15 year olds adolescents, respectively. ${ }^{60}$ In Grenada, a national study conducted in 2010 reported a mean DMFT and dmft scores of 1.03 and 11.72, respectively, among children aged 6-8 years. This study also reported a mean DMFT score of 8.4 among 14-15 year old adolescents. ${ }^{61}$ In Montserrat, a small island in the Caribbean, a national study in 2007 reported a mean DMFT score of 1.91 and a prevalence rate of $59 \%$ among adolescents aged 12 years. ${ }^{62}$

\section{Dental caries and OHRQoL}

The concept of health has become more comprehensive in recent years, reflecting the complexity of the health-disease process and the need to take both the individual's perception of their health as well as its impact on their quality of life into consideration. The epidemiological evidence of dental caries and its impact on OHRQoL provided in this review aims to further improve the understanding and management of dental caries in LACCs.

Tooth-aches are the most common symptoms of untreated carious lesions and are known to negatively affect the quality of life of individuals, as shown by a Brazilian population-based birth cohort study 
examining preschoolers. ${ }^{63}$ Another consequence of early childhood caries is its impact on the OHRQoL of children as well as their families, with studies examining Brazilian preschoolers demonstrating that both low and high caries experiences as well disease severity negatively affected the parent's and children's OHRQoL. ${ }^{64,65,66}$

These studies show that oral symptoms and functional limitations can negatively affect the child's OHRQoL by influencing their self-image and social interactions. Furthermore, treatment of dental caries at this stage of life has been shown to cause a significant improvement in the OHRQoL of preschoolers. ${ }^{67}$

In Peru, studies examining preschool children and adolescents showed that the presence of teeth with cavitated decayed dentine with or without pulpal involvement negatively affected the OHRQoL of 3 -year-old children from the lower socioeconomic strata of Lima. ${ }^{68}$ Moreover, adolescents aged 14-20 years and attending schools in the urban and rural areas of the cities of Lima and Cuzco exhibited a high prevalence of caries, which negatively affected their OHRQoL. ${ }^{69}$

In Ecuador, the impact of dental caries on the OHRQoL was evaluated in adolescents and young adults residing in the city of Quito and the presence of carious lesions along with various socioeconomic factors were found to be associated with poor quality of life in 12 year old adolescents attending public schools. ${ }^{70}$ In Colombia, young and mature adults (20-59 years old) with less than 19 teeth, evidence of root remnants and dental calculus in the oral cavity, and the absence of access to health services reported poor OHRQoL. ${ }^{71}$ A study in Chile reported compromised quality of life in $37 \%$ of individuals aged 15 years and above who exhibited pain, discomfort, and social and functional limitations. Moreover, individuals over 20 years of age were affected more than younger ones due to presentation of more severe symptoms. ${ }^{72}$ In Mexico, studies examining children and older adults reported an association between poor OHRQoL and the presence of cavitated carious lesions in children aged 8-13 years. Moreover, participants with International Caries Detection and Assessment System (ICDAS
II) $\geq 4$ exhibited approximately twice the odds of experiencing a greater negative impact on their OHRQoL compared to children with lower caries experience. ${ }^{73}$ Another study examining older adults in Mexico City reported an association between a high number of missing teeth and poor OHRQoL. ${ }^{74}$

In most cases, tooth loss is a consequence of oral disease and its location and distribution may be associated with varying severity of OHRQoL impairment. ${ }^{75} \mathrm{~A}$ 3-year follow-up study among the elderly population of southern Mexico City reported a 5\% increase in risk of developing frailty with every additional tooth lost. ${ }^{76}$ Data on the dental caries index in El Salvador, Honduras, Panama, and Mexico shows a high prevalence of unmet treatment needs, particularly in primary dentition. Evidence from the Panama National Oral Health Survey showed an increase in the number of missing teeth with aging, with $45.3 \%$ of the DMFT index in the 6-75 year old population being attributed to extracted teeth. Moreover, more than half (57.4\%) of the adult population also exhibited a need for dental prostheses. Epidemiological data from Panama and El Salvador showed that tooth loss affected urban and rural populations differently, with the latter being more severely affected by dental caries due to limited access to dental services. ${ }^{41,42}$

There is limited evidence on OHRQoL in the Caribbean countries, and currently there are only two studies that have examined this outcome among children and none that focus on adults from this region. ${ }^{77,78}$ The first study administered the Early Childhood Oral Health Impact Scale (ECOHIS) to the parents and primary caregivers of children aged 3-5-years and attending preschools in the central region of Caroni in Trinidad and Tobago. The results showed an overall low impact on OHRQoL, the most frequent of which were difficulty in eating and drinking hot or cold beverages; and being irritable or frustrated. Moreover, a negative impact on the OHRQoL was also directly associated with the severity of the lesion, suggesting that untreated carious lesions were associated with poorer OHRQoL. ${ }^{77}$ The second study examined the OHRQoL of children aged 6-7-years-old in the Dominican Republic by administering the Scale of Oral Health-Related 
Outcomes for 5-Year-Old-Children (SOHO-5) among a low-income sample. The results of this survey showed that $74 \%$ of the children faced difficulties with at least one essential life activity, and $58 \%$ and $39 \%$ of the children reported an inability to eat and drink, respectively. ${ }^{78}$

\section{Recommendations}

The recommendations below were based on the present study and paper of Sampaio et al..79

a. Development of new epidemiological studies examining unexplored aspects of the dental caries epidemic in LACCs is essential, and priority should be given to national surveys with samples representative of the population in order to produce high-quality evidence. Such studies should include samples with different age groups, including preschool and school-going children, adolescents, adults, and the elderly population. Standardization of the age groups evaluated will allow comparison of outcomes between countries. Moreover, these surveys should use a well-defined methodology and should include caries detection systems that also consider non-cavitated carious lesions.

b. The countries in the LACC region should collaborate with each other to allow greater access to regional data.

c. National surveys should also receive governmental support as they will provide robust evidence that will inform the development of oral health programs and strategies focused on reducing the dental caries burden in their countries. Public health policies should be based on scientific evidence and should include oral health promotion and dental caries prevention, control, and management measures.

d. Academic institutions should work together to improve oral health and reduce the dental caries prevalence in LACCs.

e. Further evidence on OHRQoL in LACCs is necessary, and inclusion of this component in national surveys is recommended. This type of evidence may help inform public health policies and decisions that aim to improve the OHRQoL of the population, including children, adolescents, adults, and the elderly.

f. Standardized OHRQoL tools with satisfactory psychometric properties should be selected for each age group in LACCs.

g. LACCs should establish alliances with regional and international organizations that support multi-country projects.

\section{Conclusions}

A decrease in dental caries prevalence has been observed in several LACCs. This is accompanied by a change in the distribution of the dental caries index (DMFT/dmft), with several countries reporting an increase in the prevalence of filled teeth and a reduction in the number of missing teeth. However, untreated dental carious lesions are still one of the most prevalent conditions among children and adults in this region, with dental caries affecting primary dentition decreasing to a lesser extent than those affecting permanent dentition in most LACCs except Brazil. The majority of surveys reviewed in the current study did not examine the elderly population.

OHRQoL outcomes should be included in all LACC national surveys. Governments should focus on oral health improvement programs for the population as this will not only decrease disease burden but also improve OHRQoL.

\section{Acknowledgments}

This paper was prepared for the consensus meeting titled "Dental Caries Prevalence, Prospects and Challenges for LACC", promoted by the Latin American Oral Health Association and Colgate Palmolive Co. with the support of the Federación Odontológica Latinoamericana, Sociedade Brasileira de Pesquisa Odontológica (SBPqO/Brazilian Division of IADR), and the participation of experts from the region, including representatives from national, regional and international dental associations. All participants had the opportunity to review the manuscript and make their own contributions. This paper contributed to the summary and final recommendations of the Dental Caries Regional Consensus. 
Dental caries experience and its impact on quality of life in Latin American and Caribbean countries

\section{References}

1. Porta M. A dictionary of epidemiology. 6th ed. USA: Oxford University Press; 2016.

2. Neves ET, Firmino RT, Perazzo MF, Gomes MC, Martins CC, Paiva SM, et al. Absenteeism among preschool children due to oral problems. J Public Health (Bangkok). 2016;24(1):65-72. https://doi.org/10.1007/s10389-015-0697-0

3. Narvai PC. Cárie dentária e flúor: uma relação do século XX. Cien Saude Colet. 2000;5(2):381-92. https://doi.org/10.1590/S1413-81232000000200011

4. Frencken JE, Sharma P, Stenhouse L, Green D, Laverty D, Dietrich T. Global epidemiology of dental caries and severe periodontitis - a comprehensive review. J Clin Periodontol. 2017 Mar;44 Suppl 18:S94-105. https://doi.org/10.1111/icpe.12677

5. James SL, Abate D, Abate KH, Abay SM, Abbafati C, Abbasi N, et al. Global, regional, and national incidence, prevalence, and years lived with disability for 354 diseases and injuries for 195 countries and territories, 1990-2017: a systematic analysis for the Global Burden of Disease Study 2017. Lancet. 2018 Nov;392(10159):1789-858. https://doi.org/10.1016/S0140-6736(18)32279-7

6. Engelmann JL, Tomazoni F, Oliveira MD, Ardenghi TM. Association between dental caries and socioeconomic factors in schoolchildren: a multilevel analysis. Braz Dent J. 2016 Jan-Feb;27(1):72-8. https://doi.org/10.1590/0103-6440201600435

7. Costa SM, Martins CC, Bonfim ML, Zina LG, Paiva SM, Pordeus IA, et al. A systematic review of socioeconomic indicators and dental caries in adults. Int J Environ Res Public Health. 2012 Oct;9(10):3540-74. https://doi.org/10.3390/ijerph9103540

8. Mendes EV. [Health care networks]. Cien Saude Colet. 2010 Aug;15(5):2297-305. Poruguese. https://doi.org/10.1590/S1413-81232010000500005

9. Bernabe E, Marcenes W, Hernandez CR, Bailey J, Abreu LG, Alipour V, et al. Global, regional, and national levels and trends in burden of oral conditions from 1990 to 2017: a systematic analysis for the Global Burden of Disease 2017 Study. J Dent Res. 2020 Apr;99(4):362-73. https://doi.org/10.1177/0022034520908533

10. Gimenez T, Bispo BA, Souza DP, Viganó ME, Wanderley MT, Mendes FM, et al. Does the decline in caries prevalence of Latin American and Caribbean children continue in the new century? Evidence from systematic review with meta-analysis. PLoS One. 2016 Oct;11(10):e0164903. https://doi.org/10.1371/journal.pone.0164903

11. Kassebaum NJ, Smith AG, Bernabé E, Fleming TD, Reynolds AE, Vos T, et al. Global, regional, and national prevalence, incidence, and disability-adjusted life years for oral conditions for 195 countries, 1990-2015: a systematic analysis for the global burden of diseases, injuries, and risk factors. J Dent Res. 2017 Apr;96(4):380-7. https://doi.org/10.1177/0022034517693566

12. Singh H, Maharaj RG, Naidu R. Oral health among the elderly in 7 Latin American and Caribbean cities, 1999-2000: a cross-sectional study. BMC Oral Health. 2015 Apr;15(1):46. https://doi.org/10.1186/s12903-015-0030-x

13. Corrêa-Faria P, Paixão-Gonçalves S, Paiva SM, Pordeus IA. Incidence of dental caries in primary dentition and risk factors: a longitudinal study. Braz Oral Res. 2016 May;30(1):S1806-83242016000100254. https://doi.org/10.1590/1807-3107BOR-2016.vol30.0059

14. Ellina P, Middleton N, Lambrinou E, Kouta C. Investigation of socioeconomic inequalities in health-related quality of life across Europe: a systematic review. Divers Equal Health Care. 2019;16(4): https://doi.org/10.36648/2049-5471.16.3.197

15. Sischo L, Broder HL. Oral health-related quality of life: what, why, how, and future implications. J Dent Res. 2011 Nov;90(11):1264-70. https://doi.org/10.1177/0022034511399918

16. Allison PJ, Locker D, Feine JS. Quality of life: a dynamic construct. Soc Sci Med. 1997 Jul;45(2):221-30. https://doi.org/10.1016/S0277-9536(96)00339-5

17. Kumar S, Kroon J, Lalloo R. A systematic review of the impact of parental socio-economic status and home environment characteristics on children's oral health related quality of life. Health Qual Life Outcomes. 2014 Mar;12(1):41. https://doi.org/10.1186/1477-7525-12-41

18. Haag DG, Peres KG, Balasubramanian M, Brennan DS. Oral conditions and health-related quality of life: a systematic review. J Dent Res. 2017 Jul;96(8):864-74. https://doi.org/10.1177/0022034517709737

19. Fischer RG, Lira-Junior R, Retamal-Valdes B, Figueiredo LC, Malheiros Z, Stewart B, et al. Periodontal disease and its impact on general health in Latin America. Section V: Treatment of periodontitis. Braz Oral Res. 2020;34(suppl 1). https://doi.org/10.1590/1807-3107bor-2020.vol34.0026

20. World Health Organization. Oral health survey basic methods. 4th ed. Geneva: World Health Organization; 1997.

21. Petersen PE, Bourgeois D, Ogawa H, Estupinan-Day S, Ndiaye C. The global burden of oral diseases and risks to oral health. Bull World Health Organ. 2005 Sep;83(9):661-9. https://doi.org//S0042-96862005000900011

22. Ministério da Saúde (BR). Projeto SB Brasil 2003: condições de saúde bucal da população brasileira 2002-2003: resultados principais. Brasília, DF: Ministério da Saúde; 2004. (Série C. Projetos, Programas e Relatórios).

23. Ministério da Saúde (BR). SB Brasi 2010: pesquisa nacional de saúde bucal: resultados principais. Brasília, DF: Ministério da Saúde; 2012.

24. Ministerio de Salud Pública (EC); Organización Panamericana de la Salud. Estudio epidemiológico de salud bucal en escolares fiscales menores de 15 años del Ecuador: I Parte - Estudio descriptivo. Quito: Ministerio de Salud Publica; 1996. 
25. Ministerio de Salud Pública (EC); Organización Panamericana de la Salud. Estudio epidemiológico nacional de salud Bucal en escolares menores de 15 años del Ecuador. Quito: Ministerio de Salud Publica; 2010.

26. Ministerio de Salud (PE). Publicación oficial de difusión de la dirección general de epidemiología. Boletín Epidemiológico. 2009;18(13):236-56.

27. Zúñiga ES, Porras JV. [Epidemiology of dental caries in Colombia]. Univ Odontol. 2013;32(68):177-124. Spanish.

28. Ministerio de Salud (CO). ABECÉ sobre IV Estudio Nacional de Salud Bucal "Para saber cómo estamos y saber qué hacemos". Bogotá: Ministerio de Salud; 2014.

29. Ministerio de Salud (CH). Análisis de situación de salud bucal en Chile. Santiago: Minsiterio de Salud; 2010.

30. Ministerio de Salud (PY). Encuesta nacional de salud oral. Asunción: Ministerio de Salud ; 2008.

31. Ministerio de Salud (BO). Dirección General de Servicios de Salud. Levantamiento epidemiológico índice CEO-CPOD. La Paz: Ministerio de Salud; 2015.

32. Ministerio de Salud Pública y Asistencia Social (GT). Estudio epidemiologico de caries dental y fluorosis. Ciudad de Guatemala: Ministerio de Salud Pública y Asistencia Social; 2002.

33. Carrer FC, Silva DP, Pucca-Junior GA, Rivas MG. Developing a team to improve oral health: the oral health in the Argentina Republic. São Paulo: Faculdade de Odontologia da USP; 2019.

34. Móron-Borjas AM, Córdova MY, Santana Y, Quintero L, Pirona M, Navas R, et al. Perfil epidemiológico bucal de las etnias venezolanas. Primer reporte nacional. Cienc Odontológica. 2008 Dic;5(3):11-49.

35. Ministerio de Salud Pública (UY). Comisión Honoraria de Salud Bucal. Valoración de la salud bucal de la población escolar: sector público. Montevideo: Ministerio de Salud Pública; 1992.

36. Álvarez L, Liberman J, Abreu S, Mangarelli C, Correa MB, Demarco FF, et al. Dental caries in Uruguayan adults and elders: findings from the first Uruguayan National Oral Health Survey. Cad Saude Publica. 2015 Aug;31(8):1663-72. https://doi.org/10.1590/0102-311X00132214

37. Secretaría de Salud (MX). Encuesta nacional de caries y fluorosis dental 2001. México, DF: Secretaría de Salud; 2006.

38. Mexico. Centro Nacional de Programas Preventivos y Control de Enfermedades. Informe de caries dental, encuesta nacional de caries y fluorosis dental 2011-2014. [cited 2020 Nov 30]. Available from: https://www.gob.mx/salud/cenaprece/documentos/informe-de-cariesdental-encuesta-nacional-de-caries-y-fluorosis-dental-2011-2014

39. Secretaría de Salud (MX). Informes SIVEPAB 2018. México, DF: Secretaría de Salud; 2018.

40. Medina-Solís CE, Pérez-Núñez R, Maupomé G, Casanova-Rosado JF. Edentulism among Mexican adults aged 35 years and older and associated factors. Am J Public Health. 2006 Sep;96(9):1578-81. https://doi.org/10.2105/AJPH.2005.071209

41. Cedeño-Lopez A, Lopez L, Rodulfo AC, Galvez CA, Chávez-Vargas D, Caballero N, et al. Diagnosis of the bucodental health in Panama. Panamá: Centro de Información y Documentación en Salud; 2008.

42. Aguirre-Escobar GA, Fernández-de-Quezada R, Escobar-de-González W. [Dental cavity and treatment needs prevalence according to ICDAS and DMF in schools of El Salvador]. Horiz Sanit. 2018 Sept/Dic;17(3):209-16. Spanish. https://doi.org/10.19136/hs.a17n3.2412

43. Tepe JH, Tepe LJ. A model for mission dentistry in a developing country. Front Public Health. 2017 Aug;5:119. https://doi.org/10.3389/fpubh.2017.00119

44. Ministerio de Salud (HN). Division de Salud Oral. Estudio epidemiologico de salud bucal en niños de 6, 7, 8, 12 y 15 años de Honduras. Tegucigalpa: Ministerio de Salud; 1997.

45. Solórzano I, Salas MT, Chavarría P, Beltrán-Aguilar E, Horowitz H. Prevalence and severity of dental caries in Costa Rican schoolchildren: results of the 1999 national survey. Int Dent J. 2005 Feb;55(1):24-30. https://doi.org/10.1111/j.1875-595X.2005.tb00028.x

46. Montero O, Ulate J, Rodriguez A, Mendez C, Monge L, Elias A. [Prevalence of dental caries on scholar children of 12 years old in Costa Rica]. Rev Científica Odontológica. 2011;7(2):55-63. Spanish.

47. Herrera MS, Medina-Solís CE, Minaya-Sánchez M, Pontigo-Loyola AP, Villalobos-Rodelo JJ, Islas-Granillo H, et al. Dental plaque, preventive care, and tooth brushing associated with dental caries in primary teeth in schoolchildren ages 6-9 years of Leon, Nicaragua. Med Sci Monit. 2013 Nov;19:1019-26. https://doi.org/10.12659/MSM.884025

48. Herrera MS, Medina-Solís CE, Islas-Granillo H, Lara-Carrillo E, Scougall-Vilchis RJ, Escoffié-Ramírez M, et al. Sociodemographic, socio-economic, clinical and behavioural factors modifying experience and prevalence of dental caries in the permanent dentition. West Indian Med J. 2014 Dec;63(7):752-7. https://doi.org/10.7727/wimi.2014.027

49. Künzel W, Fischer T. Caries prevalence after cessation of water fluoridation in La Salud, Cuba. Caries Res. 2000 Jan-Feb;34(1):20-5. https://doi.org/10.1159/000016565

50. Psoter WJ, Saint Jean HL, Morse DE, Prophte SE, Joseph JR, Katz RV. Dental caries in twelve- and fifteen-year-olds: results from the basic oral health survey in Haiti. J Public Health Dent. 2005;65(4):209-14. https://doi.org/10.1111/i.1752-7325.2005.tb03020.x

51. Diaz-Nicolas J, Silva-Vetri MG, Rivas-Tumanyan S, Toro MJ, Elías-Boneta AR. Prevalence of dental caries in 12-year-olds in San Pedro de Macorís, DR. P R Health Sci J. 2020 Jun;39(2):210-5. 
Dental caries experience and its impact on quality of life in Latin American and Caribbean countries

52. Collins J, Bobadilla M, Fresno MC. Indicadores de riesgo cariogénico en adolescentes de Santo Domingo, República Dominicana. Rev Clín Periodoncia Implantol Rehabil Oral. 2008;1(3):86-9. https://doi.org/10.1016/S0718-5391(08)70014-4

53. Elias-Boneta AR, Toro MJ, Rivas-Tumanyan S, Murillo M, Orraca L, Encarnacion A, et al. Persistent oral health disparity in 12-year-old Hispanics: a cross-sectional study. BMC Oral Health. 2016 Feb;16(1):10. https://doi.org/10.1186/s12903-016-0162-7

54. Elías-Boneta AR, Crespo Kebler K, Gierbolini CC, Toro Vizcarrondo CE, Psoter WJ. Dental caries prevalence of twelve year olds in Puerto Rico. Community Dent Health. 2003 Sep;20(3):171-6.

55. Estupiñán-Day SR, Baez R, Horowitz H, Warpeha R, Sutherland B, Thamer M. Salt fluoridation and dental caries in Jamaica. Community Dent Oral Epidemiol. 2001 Aug;29(4):247-52. https://doi.org/10.1034/i.1600-0528.2001.290402.x

56. Legall G. Antigua Oral Health Survey:2006: final report. Washington, DC: Organización Panamericana de la Salud; 2007.

57. Naidu R, Prevatt I, Simeon D. The oral health and treatment needs of schoolchildren in Trinidad and Tobago: findings of a national survey. Int J Paediatr Dent. 2006 Nov;16(6):412-8. https://doi.org/10.1111/j.1365-263X.2006.00755.x

58. Percival T, Edwards J, Barclay S, Sa B, Majumder MA. Early childhood caries in 3 to 5 year old children in Trinidad and Tobago. Dent J (Basel). 2019 Feb;7(1):16. https://doi.org/10.3390/dj7010016

59. Obry-Musset AM, Cahen PM, Turlot JC, Baker B, Frank RM. Dental caries and oral hygiene among 12-year-old children in Martinique, France. Community Dent Oral Epidemiol. 1991 Feb;19(1):54-5. https://doi.org/10.1111/j.1600-0528.1991.tb00107.x

60. Ministry of Health (BS). Oral health status of school children in the Commonwealth of the Bahamas. Result of a National Survey 1999-2000. Nassau: Ministry of Health; 2001.

61. Wolff MS, Hill R, Wilson-Genderson M, Hirsch S, Dasanayake AP. Nationwide 2.5-year school-based public health intervention program designed to reduce the incidence of caries in children of Grenada. Caries Res. 2016;50 Suppl 1:68-77. https://doi.org/10.1159/000439058

62. Fergus CE. Caries prevalence and experience of 12-year old children in Montserrat. West Indian Med J. 2010 Oct;59(5):573-7.

63. Boeira GF, Correa MB, Peres KG, Peres MA, Santos IS, Matijasevich A, et al. Caries is the main cause for dental pain in childhood: findings from a birth cohort. Caries Res. 2012;46(5):488-95. https://doi.org/10.1159/000339491

64. Firmino RT, Gomes MC, Clementino MA, Martins CC, Paiva SM, Granville-Garcia AF. Impact of oral health problems on the quality of life of preschool children: a case-control study. Int J Paediatr Dent. 2016 Jul;26(4):242-9. https://doi.org/10.1111/ipd.12182

65. Granville-Garcia AF, Gomes MC, Perazzo MF, Martins CC, Abreu MH, Paiva SM. Impact of caries severity/activity and psychological aspects of caregivers on oral health-related quality of life among 5-year-old children. Caries Res. 2018;52(6):570-9. https://doi.org/10.1159/000488210

66. Abanto J, Carvalho TS, Mendes FM, Wanderley MT, Bönecker M, Raggio DP. Impact of oral diseases and disorders on oral health-related quality of life of preschool children. Community Dent Oral Epidemiol. 2011 Apr;39(2):105-14. https://doi.org/10.1111/j.1600-0528.2010.00580.x

67. Abanto J, Paiva SM, Sheiham A, Tsakos G, Mendes FM, Cordeschi T, et al. Changes in preschool children's OHRQoL after treatment of dental caries: responsiveness of the B-ECOHIS. Int J Paediatr Dent. 2016 Jul;26(4):259-65. https://doi.org/10.1111/ipd.12192

68. Pesaressi E, Villena RS, Frencken JE. Dental caries and oral health-related quality of life of 3 -year-olds living in Lima, Peru. Int J Paediatr Dent. 2020 Jan;30(1):57-65. https://doi.org/10.1111/ipd.12582

69. Cadenas de Llano-Pérula M, Ricse E, Fieuws S, Willems G, Orellana-Valvekens MF. Malocclusion, dental caries and oral health-related quality of life: a comparison between adolescent school children in urban and rural regions in Peru. Int J Environ Res Public Health. 2020 Mar;17(6):2038. https://doi.org/10.3390/ijerph17062038

70. Michel-Crosato E, Raggio DP, Coloma-Valverde AN, Lopez EF, Alvarez-Velasco PL, Medina MV, et al. Oral health of 12-year-old children in Quito, Ecuador: a population-based epidemiological survey. BMC Oral Health. 2019 Aug;19(1):184. https://doi.org/10.1186/s12903-019-0863-9

71. Díaz-Cárdenas S, Meisser-Vidal MA, Tirado-Amador LR, Fortich-Mesa N, Tapias-Torrado L, González-Martínez FD. [Oral health impact on life quality in young adults at dental university clinics]. Int J Odontostomatol. 2017;11(1):5-11. Spanish. https://doi.org/10.4067/S0718-381X2017000100001

72. Ministerio de Salud (CH). Diagnóstico de situación de salud bucal. [cited 2020 Nov 30]. Available from: https://www.minsal.cl/portal/ url/item/7dc33df0bb34ec58e04001011e011c36.p

73. Molina-Frechero N, Nevarez-Rascón M, Nevarez-Rascón A, González-González R, Irigoyen-Camacho ME, Sánchez-Pérez L, et al. Impact of dental fluorosis, socioeconomic status and self-perception in adolescents exposed to a high level of fluoride in water. Int J Environ Res Public Health. 2017 Jan;14(1):73. https://doi.org/10.3390/ijerph14010073

74. Montes-Cruz C, Juárez-Cedilloher T, Cárdenas-Bahena A, Rabay-Gánem C, Heredia-Ponce E, García-Peña C, et al. [Behavior of the Geriatric/General Oral Health Assessment Index (GOHAl) and Oral Impacts on Daily Performances (OIDP) in a senior adult population in Mexico City]. Rev Odontol Mex. 2014;18(2):111-9. Spanish. https://doi.org/10.1016/S1870-199X(14)72060-9

75. Gerritsen AE, Allen PF, Witter DJ, Bronkhorst EM, Creugers NH. Tooth loss and oral health-related quality of life: a systematic review and meta-analysis. Health Qual Life Outcomes. 2010 Nov;8(1):126. https://doi.org/10.1186/1477-7525-8-126 
76. Castrejón-Pérez RC, Jiménez-Corona A, Bernabé E, Villa-Romero AR, Arrivé E, Dartigues JF, et al. Oral disease and 3-year incidence of frailty in Mexican older adults. Journals Gerontol Ser A Biol Sci. J Gerontol A Biol Sci Med Sci. 2017 Jul;72(7):951-7. https://doi.org/10.1093/gerona/glw201

77. Naidu R, Nunn J, Donnelly-Swift E. Oral health-related quality of life and early childhood caries among preschool children in Trinidad. BMC Oral Health. 2016 Dec;16(1):128. https://doi.org/10.1186/s12903-016-0324-7

78. Abreu-Placeres N, Garrido LE, Féliz-Matos LE. Cross-cultural validation of the scale of oral health-related outcomes for 5-year-old-children with a low-income sample from the Dominican Republic. J Int Soc Prev Community Dent. 2017 May-Jun;7(3):84-9. Htttps://doi.org/10.4103/jispcd.JISPCD_513_16

79. Sampaio FC, Bönecker M, Paiva SM, Martignon S, Ricomini Filho AP, Pozos-Guillen, et al. Dental caries prevalence, prospects, and challenges for Latin America and Caribbean countries: a summary and final recommendations from a Regional Consensus. Braz Oral Res. 2021;35(suppl 1):056. https://doi.org/10.1590/1807-3107bor-2021.vol35.0056 